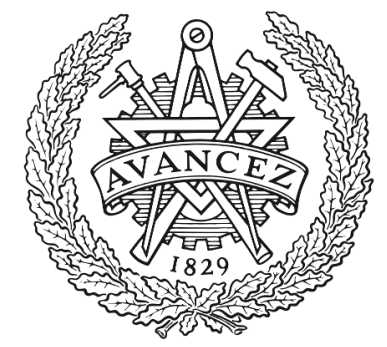

CHALMERS

UNIVERSITY OF TECHNOLOGY

\title{
Stochastic Operation Scheduling Model for a Swedish Prosumer with PV and BESS in Nordic Day-Ahead Electricity Market
}

Downloaded from: https://research.chalmers.se, 2023-04-26 15:35 UTC

Citation for the original published paper (version of record):

Agathokleous, C., Le, A., Steen, D. (2019). Stochastic Operation Scheduling Model for a Swedish Prosumer with PV and BESS in Nordic

Day-Ahead Electricity Market. 2019 IEEE Milan PowerTech, PowerTech 2019.

http://dx.doi.org/10.1109/PTC.2019.8810651

N.B. When citing this work, cite the original published paper. 


\title{
Stochastic Operation Scheduling Model for a Swedish Prosumer with PV and BESS in Nordic Day-Ahead Electricity Market
}

\author{
Christos Agathokleous, Le Anh Tuan, David Steen \\ Department of Electrical Engineering, Chalmers University of Technology \\ 41296 Gothenburg, Sweden \\ christos.agathokleous@chalmers.se
}

\begin{abstract}
In this paper, an optimal stochastic operation scheduling model is proposed for a prosumer owning photovoltaic (PV) facility coupled with a Battery Energy Storage System (BESS). The objective of the model is to maximize the prosumer's expected profits. A two-stage stochastic mixed-integer nonlinear optimization (SMINLP) approach is used to cope with the parameters' uncertainties. Artificial Neural Networks (ANN) are used to forecast the markets' prices and the standard scenario reduction algorithms are applied to handle the computational tractability of the problem. The model is applied to a case study using data from the Nordic electricity markets and historical PV production data from the Chalmers University of Technology campus, considering a scaled up 5MWp power capacity. The results show that the proposed approach could increase the revenue for the prosumer by up to $11.6 \%$ as compared to the case without any strategy. Furthermore, the sensitivity analysis of BESS's size on the expected profit shows that increasing BESS size could lead to an increase in the net profits.
\end{abstract}

Keywords - Battery energy storage systems (BESS), solar prosumer, stochastic mixed-integer nonlinear optimization problem (SMINLP), Swedish balance settlement system.

\section{NOMENCLATURE}

$$
\begin{aligned}
& \text { A. Indices } \\
& \mathrm{t} \quad \text { Time period Index. }
\end{aligned}
$$

$\omega \quad$ Scenario Index.

\section{B. Parameters}

eff Charging (round-trip) efficiency of the battery.

$E_{\text {init }}^{\text {Bat }} \quad$ Energy stored at the beginning of the bidding period, MWh.

$P_{\max }^{\text {Bat }} \quad$ Maximum power of the battery storage system $(>0)$, MW.

$E_{\text {max }}^{\text {Bat }}$ Maximum energy that can be stored in the battery, MWh.

$E_{\min }^{\text {Bat }}$ Minimum energy that can be stored in the battery, MWh.

$\mathrm{P}_{t, \omega}^{P V} \quad$ Photovoltaic forecasted power production at time $t$ and scenario $\omega$, MW.

$P_{\max }^{P V} \quad$ Maximum power that can be produced by the

The work presented in this paper has been partially funded by Urban Innovative Actions program to the Fossil Free Energy Districts (FED) project (No. UIA01-209). photovoltaic, MW.

$p r_{t, \omega}^{E L} \quad$ Forecasted Nord Pool spot market price at time $\mathrm{t}$ and scenario $\omega$.

$\lambda_{t, \omega}^{P D} \quad$ Penalty for positive imbalance applied for consumption at time $\mathrm{t}$ and scenario $\omega$.

$\lambda_{t, \omega}^{N D} \quad$ Penalty for negative imbalance applied for consumption at time $\mathrm{t}$ and scenario $\omega$.

$\lambda_{t, \omega}^{P S} \quad$ Penalty for positive imbalance applied for production at time $t$ and scenario $\omega$.

$\lambda_{t, \omega}^{N S} \quad$ Penalty for negative imbalance applied for production at time $t$ and scenario $\omega$.

$W_{\omega} \quad$ Probability of scenario $\omega$.

C. Variables

$P_{t}^{C h} \quad$ Actual power charged by battery at time t, MW.

$P_{t}^{\text {Dis }} \quad$ Actual power delivered by the battery at time t, MW.

$E_{t}^{\text {Bat }} \quad$ Energy stored in the battery at time t, MWh.

Bid $_{t}^{S} \quad$ Supply bid submitted in Nord Pool spot market at time t, MWh.

Bid $_{t}^{D} \quad$ Demand bid submitted in Nord Pool spot market at time t, MWh.

Dev $v_{t, \omega}^{D} \quad$ Imbalance between demand bid and measured consumption at time $\mathrm{t}$ and scenario $\omega$.

$D e v_{t, \omega}^{P D} \quad$ Positive imbalance between demand bid and measured consumption at time $\mathrm{t}$ and scenario $\omega$.

$D e v_{t, \omega}^{N D} \quad$ Negative imbalance between demand bid and measured consumption at time $t$ and scenario $\omega$.

$D e v_{t, \omega}^{S} \quad$ Imbalance between supply bid and measured production at time $\mathrm{t}$ and scenario $\omega$.

$D e v_{t, \omega}^{P S} \quad$ Positive imbalance between supply bid and measured production at time $t$ and scenario $\omega$.

$D e v_{t, \omega}^{N S} \quad$ Negative imbalance between supply bid and measured production at time $t$ and scenario $\omega$.

Mes $_{t \omega}^{P} \quad$ Measured production at time t and scenario $\omega$.

$\operatorname{Mes}{ }_{t, \omega}^{t, \omega}$ Measured consumption at time $\mathrm{t}$ and scenario $\omega$.

D. Binary Variables
$S_{t}^{C h} \quad$ Charging state of the battery at time t, ( 1 for 


$$
\begin{gathered}
S_{t, \omega}^{M e t} \\
\mathrm{~S}_{t, \omega}^{(\operatorname{Im}) D} \\
\mathrm{~S}_{t, \omega}^{(\operatorname{Im}) S}
\end{gathered}
$$

charging state, 0 otherwise).

Metering State, (1 for consumption, 0 for production).

Type of demand imbalance at time $t$ and scenario $\omega$ ( 1 for positive imbalance, 0 for negative).

Type of supply imbalance at time $\mathrm{t}$ and scenario $\omega$ ( 1 for positive imbalance, 0 for negative).

\section{INTRODUCTION}

Photovoltaic installations are growing at an exponential rate worldwide. This trend has also been noticed in Sweden in the last decade [1]. Since the technologies of the photovoltaic panels are improving, the costs are decreasing, and the European Union gives incentives for green and renewable energy, an increasing number of market actors invest in PV power plants [2]. Nevertheless, this type of production has some important drawbacks; for instance, the power output of these plants fluctuates, and the prediction of the solar irradiation frequently differs from the actual one. Concerning this, the potential deviation between the bid capacity and the actual production is penalized. Therefore, the participation of the PV producers in the Day Ahead market bears a risk and an appropriate bidding strategy should be deployed.

Significant research has been carried out in order to determine the optimal bidding strategy of renewable energy resources. In [3] an affinely adjustable robust bidding strategy is proposed, pairing a PV power plant with a BESS to cope with the uncertainties of solar production and electricity prices. Nonetheless, the stochastic nature of imbalance prices is not taken into account in [3].

In this respect, several studies have investigated new approaches to optimally utilize BESS in power markets. A novel model is presented in [4] for optimal scheduling and bidding of a battery storage in both day-ahead and real-time markets. On the one hand, the receding horizon algorithm utilized in [4] can decrease the risk of stochastic revenues, updating the storage system's scheduling continuously as new forecasts become available. On the other hand, the frequent charge-discharge cycling of the BESS may lead to a reduction of its expected lifetime. Moreover, the high response of BESS makes them suitable to support ancillary services into the grid. The simultaneous offering in dayahead, spinning reserve and regulation markets is presented in [5], using robust optimization. Although the results showed that participation in multi-market environments increases the profit, this joint participation could degrade the battery due to continuous cycling. To consider BESS degradation, the authors in [6] adopted a battery cycle life model into an optimization problem to determine the optimal bidding in day-ahead spinning reserve and regulation markets

To overcome the price, load and renewable energy production forecast fluctuations, stochastic approaches have been widely used. Authors in [7] deal with the uncertainty of the market prices due to high penetration of renewable energy resources, to optimally schedule the battery storage systems and participate in energy and reserve markets. In [8] a stochastic optimization model is proposed for optimizing the microgrid operations including BESS schedules, dealing with the stochasticity generation of PVs and time-varying demand.

The main contribution of this paper is to develop an optimal operation scheduling model for a prosumer owning a PV plant combined with a battery energy storage system and participating in the Nordic day-ahead electricity market. The model can support the prosumer to optimize its participation in the Nordic day-ahead electricity market and manage its power imbalance efficiently within the Swedish imbalance settlement model, considering the stochasticity of parameters in markets' prices, regulating power directions as well as solar power production. As the result, the prosumer using the proposed model could achieve a reduction of the imbalance costs and could increase its expected net profit.

The model is formulated as a two-stage stochastic mixedinteger nonlinear optimization problem (SMINLP) to handle the uncertainty factors with the objective being the maximization of the prosumer's expected profits. ANNs are used to forecast the markets' prices and standard reduction algorithms are adopted to reduce the computational burden of the problem. It is assumed that the prosumer acts as a price taker and that the bids, will be always accepted in the day-ahead market (i.e. submit supply bids with zero price and demand bids with the highest possible price). Although, this assumption may not be acceptable in other markets, appropriate modification in the algorithm could tackle this. The proposed approach is applied to a case study using input data from the Nordic electricity markets and historical PV production data from the Chalmers University of Technology campus. The PV power capacity is assumed to be $5 \mathrm{MWp}$ and is paired with different BESS capacities. Furthermore, the feasibility and the effectiveness of the proposed approach, as well as the impact of the BESS size on the weekly net expected profit for all seasons are presented through the different Cases.

The rest of the paper is organized as follows: Section II describes the current Nordic electricity market structure and the current Swedish Balance Settlement System. Section III presents the mathematical formulation of the proposed model. In Section IV the case study is described and in Section V the relevant results are presented. Finally, conclusions are drawn in Section VI.

\section{MARKET FRAMEWORK}

The current Nordic electricity market consists of a number of specific markets, based on the timeline of the bids. These markets are the Financial market, Day-Ahead market (Elspot), the Intraday market (Elbas) and the Regulating power market [9]. A brief description of the aforementioned markets follows.

The Financial market is a commercial market, where price securing contracts are traded. There is no physical delivery for these contracts and the system marginal price is used as the reference price for this market [9].

Nord Pool Day-Ahead (Elspot) market is the main area for trading power in the Nordic electricity system. A daily auction runs and establishes a price for each hour of the next day. The bids must be submitted before 12:00 CET. 
TABLE I. ONE-PRICE MODEL APPLIED TO CONSUMERS

\begin{tabular}{ccc}
\hline $\begin{array}{c}\text { Electricity System } \\
\text { Situation }\end{array}$ & $\begin{array}{c}\text { Consumer utilized } \\
\text { more than planned }\end{array}$ & $\begin{array}{c}\text { Consumer utilized } \\
\text { less than planned }\end{array}$ \\
\hline $\begin{array}{c}\text { Up-regulation (not } \\
\text { enough electricity } \\
\text { in the system) }\end{array}$ & $\begin{array}{c}\text { Pay regulating } \\
\text { power price (higher } \\
\text { than Spot price) }\end{array}$ & $\begin{array}{c}\text { Receive regulating } \\
\text { power price (higher } \\
\text { than Spot price) }\end{array}$ \\
\hline $\begin{array}{c}\text { Down-regulation } \\
\text { (excessive electricity } \\
\text { in the system) }\end{array}$ & $\begin{array}{l}\text { Pay regulating } \\
\text { power price (lower } \\
\text { than Spot price) }\end{array}$ & $\begin{array}{c}\text { Receive regulating } \\
\text { power price (lower } \\
\text { than Spot price) }\end{array}$ \\
\hline
\end{tabular}

TABLE II. TWO-PRICE MODEL APPLIED TO PRODUCERS

\begin{tabular}{ccc}
\hline $\begin{array}{c}\text { Electricity System } \\
\text { Situation }\end{array}$ & $\begin{array}{c}\text { Producer produced } \\
\text { more than planned }\end{array}$ & $\begin{array}{c}\text { Producer produced } \\
\text { less than planned }\end{array}$ \\
\hline $\begin{array}{c}\text { Up-regulation (not } \\
\text { enough electricity } \\
\text { in the system) }\end{array}$ & Receive Spot price & $\begin{array}{c}\text { Pay regulating } \\
\text { power price (higher } \\
\text { than Spot price) }\end{array}$ \\
\hline $\begin{array}{c}\text { Down-regulation } \\
\text { (excessive electricity } \\
\text { in the system) }\end{array}$ & $\begin{array}{c}\text { Receive regulating } \\
\text { power price (lower } \\
\text { than Spot price) }\end{array}$ & Pay Spot price \\
\hline
\end{tabular}

Hourly bids are announced typically at 12:42 CET and from 00:00 CET the next day, power is delivered according to the contracts agreed and the clearing results of the market. According to [9] the minimum bid capacity is $0.1 \mathrm{MWh}$

The Intraday (Elbas) market complements the Elspot market, giving to participants the chance to reduce any deviation between the bidding power and the actual production or consumption. Moreover, the prices are set based on a pay-as-bid policy and the electricity can be traded from the time the Elspot market closes, up to 45 minutes before the operating hour.

Finally, the Transmission System Operator (TSO) of each country is responsible for ensuring that the transmission system functions reliably. Svenska kraftnät is the Swedish TSO and is responsible for the final balance during each operating hour, buying regulation services from balance providers with suitable resources through the Regulating power market. During the day after the energy is delivered, the market actors need to settle their imbalances with the TSO. In Sweden, a two-price balance settlement system is applied for production and a one-price balance settlement system for consumption, as illustrated in Tables I and II [9].

As it can be observed from Tables I and II, the two-price system gives incentives to producers to minimize their deviations, while in the one-price system consumers can profit from their imbalances when they utilized less than planned and the up-regulation is the dominant regulation direction or when they utilized more than planned and the down-regulation is the dominant direction. Considering the critical role of the metering data from the imbalance settlement perspective, the current metering rules applied to producers are described below

Production metering in the Nordic Imbalance Settlement Model is based on net metering. It means that, the metered production is calculated after subtraction of the own consumption used for power generation. In Sweden, there is no legislation that defines the own consumption of the production plant [10]. In this respect, a BESS can be considered as the own consumption of the PV power plant. If the produced energy exceeds the own consumption in a specific hour, it is reported as production, and hence the measured consumption is reported equal to zero.
Respectively, if the own consumption exceeds the production, it is reported as consumption and measured production is reported equal to zero. It should be noted that both prosumer's production and consumption plans are settled. For example, if a prosumer had a production plan of $10 \mathrm{MWh}$ and a consumption plan of $0 \mathrm{MWh}$. In the delivery hour, the consumption was actually $2 \mathrm{MWh}$, then it will be settled with both the production imbalance of 10 MWh and the consumption imbalance of $2 \mathrm{MWh}$ [11]

\section{MATHEMATICAL FORMULATION}

The optimal bidding strategy and scheduling model of the PV-BESS prosumer is described in this section. The outputs from the model are values of first-stage variables, including the optimal sizes of hourly bids in the wholesale market and the dispatch of BESS.

1) Objective function: The objective function of the model is the maximization of the total expected profit of the prosumer and is formulated as:

$$
\begin{aligned}
& \operatorname{Max} \sum_{t, \omega}\left\{W _ { \omega } \left[p r_{t, \omega}^{E L}\left(\operatorname{Bid}_{t}^{S}-\operatorname{Bid}_{t}^{D}\right)+\lambda_{t, \omega}^{P S} \operatorname{Dev} v_{t, \omega}^{P S}\right.\right. \\
& \left.\left.-\lambda_{t, \omega}^{N S} \operatorname{Dev}_{t, \omega}^{N S}+\lambda_{t, \omega}^{P D} \operatorname{Dev}_{t, \omega}^{P D}-\lambda_{t, \omega}^{N D} \operatorname{Dev}_{t, \omega}^{N D}\right]\right\}
\end{aligned}
$$

The first term corresponds to the revenue from selling the energy to the market minus the cost of buying energy from the market. The other four terms add the imbalances that the PV-BESS prosumer is required to pay if the imbalance is negative or to get paid if the imbalance is positive. It should also be mentioned that model's time horizon is equal to 24 hours

The objective function is subject to the constraints below:

2) BESS Power Rating and Energy Constraints: The charging/discharging power and the energy level of the BESS must be within its maximum and minimum limits as shown in (2)-(4). The dynamic energy state of the BESS over the given planning horizon is given by (5), (6). The binary variable $S_{t}^{C h}$, prevents the simultaneous charging and discharging.

$0 \leq P_{t}^{C h} \leq P_{\max }^{B a t} S_{t}^{C h}, \quad \forall \mathrm{t}$

$0 \leq P_{t}^{\text {Dis }} \leq P_{\max }^{\text {Bat }}\left(1-S_{t}^{C h}\right), \quad \forall \mathrm{t}$

$E_{\text {min }}^{\text {Bat }} \leq E_{t}^{\text {Bat }} \leq E_{\text {max }}^{\text {Bat }}, \quad \forall \mathrm{t}(4)$

$E_{t}^{\text {Bat }}=E_{\text {bat }}+$ eff $\cdot P_{t}^{C h}-P_{t}^{\text {Dis }}, \quad \mathrm{t}=2 \ldots \mathrm{T}$

$E_{1}^{\text {Bat }}=E_{\text {init }}^{\text {Bat }}+e f f \cdot P_{1}^{C h}-P_{1}^{\text {Dis }}, \quad \forall \omega$

3) Bid Constraints: Supply and demand bids in the dayahead market are constrained by the maximum and minimum limits of the BESS and PV plant as shown in (7)(8).

$0 \leq \operatorname{Bid}_{t}^{S} \leq P_{\text {max }}^{B a t}+P_{\text {max }}^{P V}, \quad \forall \mathrm{t}$
$0 \leq$ Bid $_{t}^{D} \leq P_{\text {max }}^{\text {Bat }}, \quad \forall \mathrm{t}$ 
4) Metering Status: As described in Section II, the metering state determines the final imbalance of production and consumption plan. It is implemented, utilizing the auxiliary binary variable $S_{t, \omega}^{M e t}$ and the constraints (9) and (10). When $S_{t, \omega}^{M e t}$ is equal to zero, it represents a metered production of the PV-BESS prosumer and when the value is equal to one, it represents a metered consumption, respectively.

The meter's measurements for each hour and each scenario are defined in (11) and (12).

$$
\begin{aligned}
& S_{t, \omega}^{M e t}\left(P_{t, \omega}^{P V}+P_{t}^{D i s}-P_{t}^{C h}\right) \leq 0, \quad \forall \mathrm{t}, \omega \\
& \left(1-S_{t, \omega}^{M e t}\right)\left(P_{t, \omega}^{P V}+P_{t}^{D i s}-P_{t}^{C h}\right) \geq 0, \quad \forall \mathrm{t}, \omega \\
& \operatorname{Mes}_{t, \omega}^{P}=\left(P_{t, \omega}^{P V}+P_{t}^{D i s}-P_{t}^{C h}\right)\left(1-S_{t, \omega}^{M e t}\right), \forall \mathrm{t}, \omega \\
& M e s_{t, \omega}^{C}=\left(P_{t}^{C h}-P_{t, \omega}^{P V}-P_{t}^{D i s}\right) S_{t, \omega}^{M e t}, \forall \mathrm{t}, \omega
\end{aligned}
$$

5) Imbalance constraints: Imbalances are calculated as the difference between the actual outcome and the bids in the market and are represented by (13) and (14). As mentioned earlier, the bids are assumed to be accepted all the time. An imbalance can be either positive, when the actual production is higher than the offer bid (actual consumption is less than the demand bid), or negative when the offer bid is higher than the actual production (actual consumption is higher than the demand bid). It is implemented using the auxiliary binary variables $\mathrm{S}_{t, \omega}^{(\mathrm{Im}) D / S}$. When $\mathrm{S}_{t, \omega}^{(\mathrm{Im}) D}$ is equal to one, the variable $D e v_{t, \omega}^{D}$ takes positive value as can be seen in (15)-(17), thus the demand bid is higher than the actual consumption. Respectively, when $\mathrm{S}_{t, \omega}^{(\mathrm{Im}) D}$ is equal to zero, the variable $D e v_{t, \omega}^{D}$ is negative, thus the demand bid is less than the actual consumption. In the same way, the variable $\mathrm{S}_{t, \omega}^{(\mathrm{Im}) S}$ determines whether the imbalance between the actual production and the offer bid is positive or negative through (18)-(20).

$$
\begin{aligned}
& \operatorname{Dev}_{t, \omega}^{D}=B i d_{t}^{D}-M e s_{t, \omega}^{C}, \quad \forall \mathrm{t}, \omega \\
& D e v_{t, \omega}^{S}=M e s_{t, \omega}^{P}-B i d_{t}^{S}, \forall \mathrm{t}, \omega \\
& D e v_{t, \omega}^{D}=D e v_{t, \omega}^{P D}-\operatorname{Dev}_{t, \omega}^{N D}, \quad \forall \mathrm{t}, \omega \\
& 0 \leq D e v_{t, \omega}^{P D} \leq P_{\max }^{B a t} \mathrm{~S}_{t, \omega}^{(\mathrm{Im}) D}, \quad \forall \mathrm{t}, \omega \\
& 0 \leq D e v_{t, \omega}^{N D} \leq P_{\max }^{B a t}\left(1-\mathrm{S}_{t, \omega}^{(\mathrm{Im}) D}\right), \quad \forall \mathrm{t}, \omega \\
& D e v_{t, \omega}^{S}=D e v_{t, \omega}^{P S}-D e v_{t, \omega}^{N S}, \quad \forall \mathrm{t}, \omega \\
& 0 \leq D e v_{t, \omega}^{P S} \leq\left(P_{\max }^{B a t}+P_{\max }^{P V}\right) \mathrm{S}_{t, \omega}^{(\mathrm{Im}) S}, \quad \forall \mathrm{t}, \omega \\
& 0 \leq D e v_{t, \omega}^{N S} \leq\left(P_{\max }^{B a t}+P_{\max }^{P V}\right)\left(1-\mathrm{S}_{t, \omega}^{(\mathrm{Im}) S}\right), \quad \forall \mathrm{t}, \omega
\end{aligned}
$$

The model is of the type SMINLP and is implemented in GAMS and solved using BONMIN solver [12]. The running time of the model was less than 15 minutes, which is acceptable for offline scheduling.

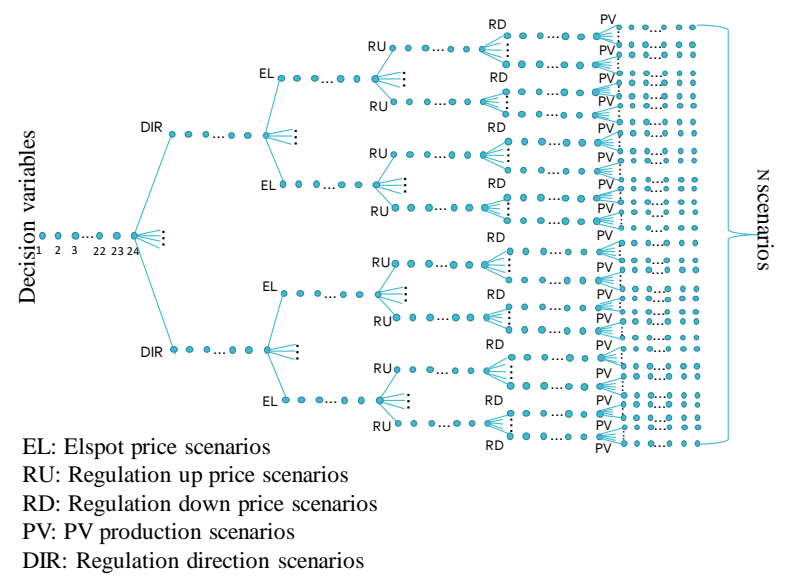

Figure 1. Scenario tree representation

\section{CASE StUdy: DESCRIPTION AND APPROACH}

\section{A. Description}

A case study was performed to test the proposed model. The case study considers that the prosumer participates in the Nord Pool spot market, owning a photovoltaic power plant with $5 \mathrm{MWp}$ capacity, combined with a BESS with various sizes. The simulations have been carried out for one week in the middle of each season of the year 2017. In total, 5 cases have been considered:

- Case-1: 2 MW/4 MWh BESS max capacities.

- Case-2: $1 \mathrm{MW} / 4 \mathrm{MWh}$ BESS max capacities.

- Case-3: $1 \mathrm{MW} / 2 \mathrm{MWh}$ BESS max capacities.

- Case-4: No BESS is utilized.

- Case-5: Selling PV production to an aggregator.

In Case-5, it is considered that the prosumer sells the electricity production to a retailer to avoid any penalty due to imbalances and no BESS is used. Case- 2 has been selected as the base case of the study.

The historical irradiance data on the roof of one of the Chalmers' building are obtained and afterwards the photovoltaic production is estimated, utilizing the model presented in [13]. The data was scaled up to $5 \mathrm{MW}$, corresponding approximately to the potential maximum solar production in Chalmers' campus, when all buildings' roofs are equipped with photovoltaic panels. It should also be noted that initially the batteries were fully charged, the maximum depth of discharge was considered $100 \%$ of the nominal capacity and the battery round-trip was equal to $80 \%$.

Four main sets of input data were used in this case study: a) Day-ahead market prices, b) Regulation market prices, c) Regulating direction, d) Photovoltaic power production. To deal with the uncertainty of these parameters, a scenario tree is constructed, where each of these parameters constitutes a different type of node-vector set, as it is shown in Fig. 1.

Moreover, the value of the stochastic solution (VSS) metric is used to evaluate the economic benefit of the stochastic model, compared to its deterministic counterpart, and it is defined as [14]: 


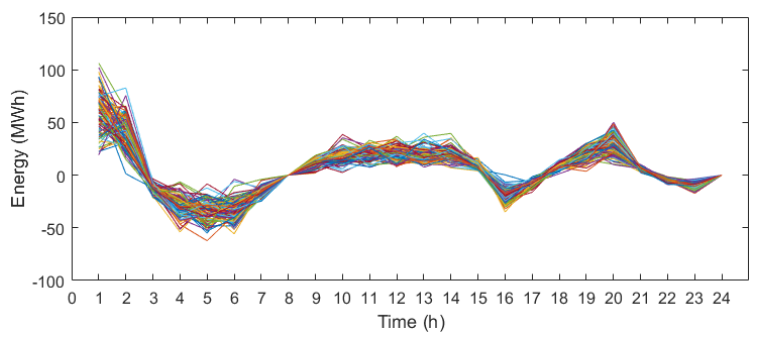

Figure 2. Regulation direction (up/down) scenarios on the $14^{\text {th }}$ of May 2017

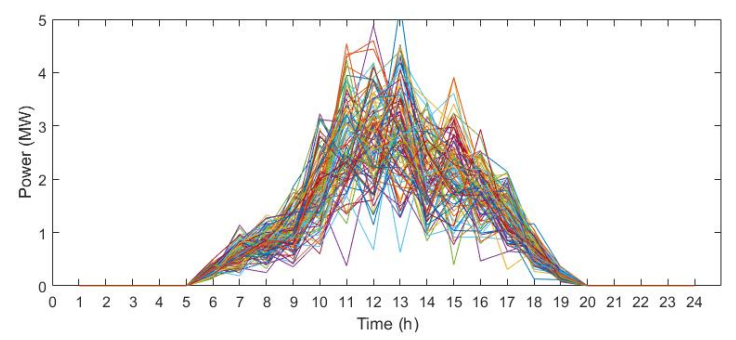

Figure 3. Solar production scenarios on the $19^{\text {th }}$ of August 2017.

$$
V S S=z^{S^{*}}-z^{D^{*}}
$$

where, $z^{S^{*}}$ is the optimal solution of the stochastic problem and $z^{D^{*}}$ is the evaluation of the expected value solution when all first-stage variables of the stochastic problem are replaced with their expected values.

\section{B. Scenarios Generation}

MATLAB's Artificial Neural Network (ANN) toolbox is utilized to forecast the Nord Pool spot market prices 36hours ahead and the up/down regulation market prices, using historical data for training, which are available in [9]. For each of these parameters, a total of 100 scenarios are generated through the forecast errors' Frequency Distribution of the ANN. To handle the computational tractability of the problem, the scenarios were reduced to 3 using a scenario reduction package SCENRED in GAMS [15].

For the regulation direction scenarios, the up/down regulating volumes [9] are considered as the forecast values, and the forecast error is represented by a normal distribution function [16]. The difference between the forecasted up/down volumes indicates the regulating direction. For the photovoltaic production scenarios, the same technique is employed [16]. For each parameter, as described previously, 100 scenarios are generated and then are reduced to 3 through SCENRED.

Fig. 2 and Fig. 3 illustrate the regulation direction and

TABLE III. PARAMETERS’ REDUCED SCENARIOS

\begin{tabular}{|c|c|c|c|}
\hline & $\begin{array}{c}\text { Scenario 1 } \\
\text { Value / Prob }\end{array}$ & $\begin{array}{c}\text { Scenario 2 } \\
\text { Value / Prob }\end{array}$ & $\begin{array}{c}\text { Scenario 3 } \\
\text { Value / Prob }\end{array}$ \\
\hline Nord Pool spot price & $26 € / 0.9294$ & $40.9 € / 0.0688$ & $186.8 € / 0.0018$ \\
\hline Up regulation price & $26 € / 0.6579$ & $46.1 € / 0.3153$ & $299.2 € / 0.0269$ \\
\hline Down regulation price & $17.7 € / 0.9908$ & $3.5 € / 0.0064$ & $0.09 € / 0.0029$ \\
\hline Regulating Direction & $110.4 \mathrm{MW} /$ & $144.1 \mathrm{MW} /$ & $\begin{array}{c}117.4 \mathrm{MW} / \\
0.16\end{array}$ \\
\hline PV generation & 0.21 & 0.63 & $0.8049 \mathrm{MW} /$ \\
& $1.6 \mathrm{MW} / 0.41$ & $1.8 \mathrm{MW} / 0.45$ & 0.14 \\
\hline
\end{tabular}

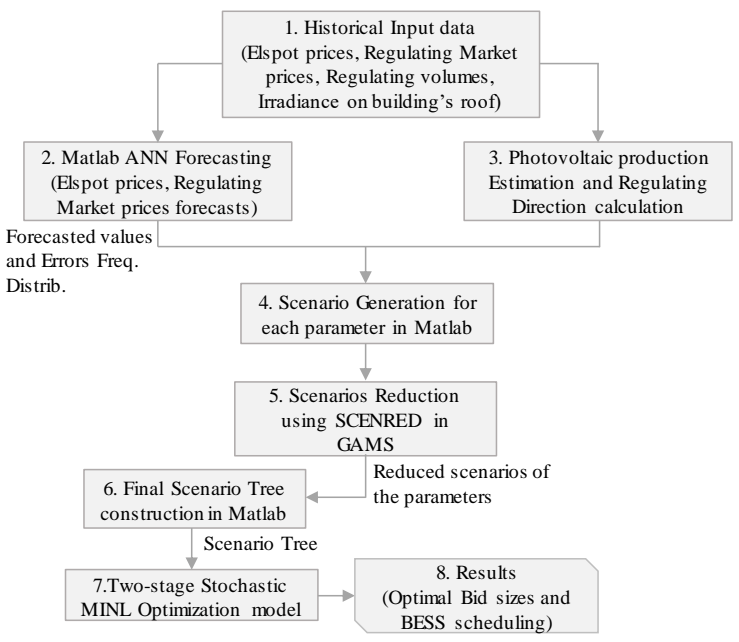

Figure 4. Flowchart diagram of the study approach.

PV production scenarios for 24 hours, respectively. The total number of the final scenarios is equal to $243\left(3^{5}\right)$. In Table III the values and their respective probabilities of the reduced scenarios for each parameter are demonstrated for an indicative hour.

\section{Study Approach}

Initially, all the input data are imported into MATLAB and the scenarios for each parameter are generated. Afterwards, GAMS modelling language is called through MATLAB to reduce the number of scenarios and the scenario tree is constructed. Finally, GAMS is employed again to solve the SMINLP model and get the optimal bid sizes and BESS scheduling. The overall procedure of the case study is shown in Fig. 4.

\section{RESULTS AND DISCUSSIONS}

\section{A. Schedule of BESS and Bid Sizes}

Fig. 5 depicts the optimal submitted demand and supply bids by the prosumer in the day ahead market, as well as the optimal schedule of the BESS, for 4 selected days in Case-2 (base case). The results have been obtained by applying the proposed model for each day separately, since the time horizon of the algorithm was 24 hours. As it can be observed, the prosumer for some hours submits non-zero demand bids, although the charging power of the battery is zero that time. This behavior can be interpreted if we take into consideration the expected regulation direction forecast as well as the net metering rules, since the one-price settlement system is applied to the imbalances of consumption and a potential profit could be achieved. Moreover, the results show that the BESS could reduce the imbalance between the expected PV production and dayahead offers.

\section{B. Sensitivity Analysis}

Table IV shows how the weekly expected profits change when varying the sizes of BESS. Investing on a 2MW/4MWh BESS (Case-1) instead of a 1MW/4MWh (base case) yields to an increased profit of $5.6 \%$. In base case, the total profit is expected to rise by almost $1.79 \%$ in 


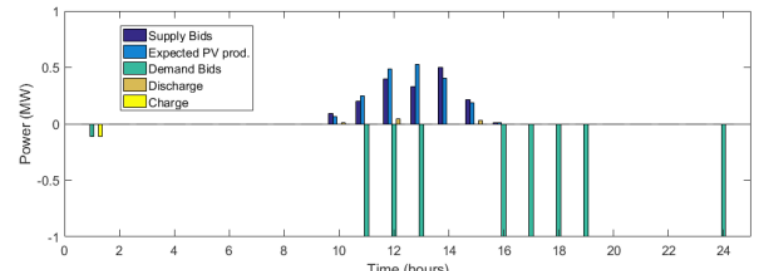

(a)

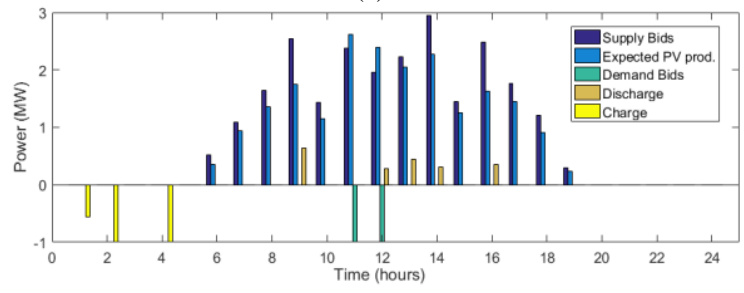

(b)

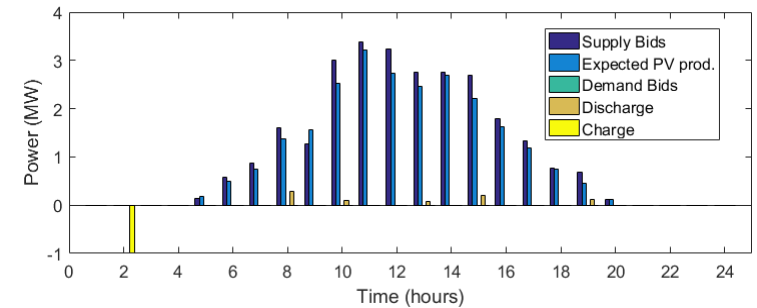

(c)

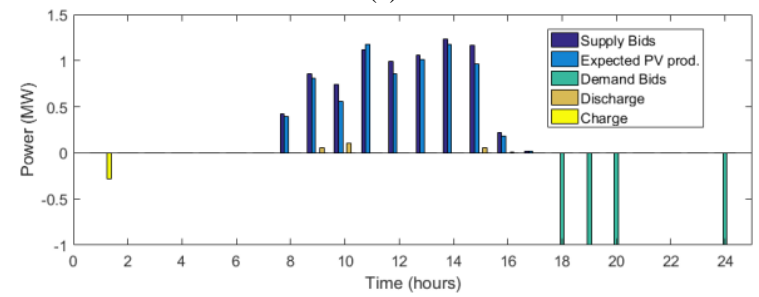

(d)

Figure 5. Day-ahead bids, charging/discharging power of PVBESS prosumer for 24 hours. (a) $24^{\text {th }}$ of January. (b) $24^{\text {th }}$ of April. (c) $24^{\text {th }}$ of July. (d) $16^{\text {th }}$ of October.

comparison with Case-3.

Comparing base case with Case- 5 the profit is higher by almost $6.4 \%$ and when base case is compared with Case- 4 the expected profit is higher by $9.5 \%$. Consequently, when the prosumer utilizes a $2 \mathrm{MW}-4 \mathrm{MWh}$ the economic benefit can be increased by up to $11.6 \%$ compared with Case-5, validating the effectiveness of the proposed model. Finally, the VSS demonstrates that the stochastic model performs better than the deterministic model by $8.2-10.3 \%$, depending on the properties of the utilized BESS.

In this case study, it was shown that an increase in the BESS capacities could increase the prosumer's profitability by decreasing the imbalances between the expected PV production and the submitted offers and by selling (buying) energy according to the market prices and regulation direction, discharging (charging) the BESS.

\section{CONCLUSIONS}

This paper proposed an optimal operation scheduling model for a PV-BESS prosumer participating in Nordic day-ahead market.

The case study results demonstrate that the operation scheduling model could help decrease the imbalance cost between bidding power and expected PV production for the prosumer by optimally scheduling the charging and
TABLE IV. WEEKLY EXPECTED PROFITS FOR EACH CASE

\begin{tabular}{|c|c|c|c|c|c|c|}
\hline \multicolumn{7}{|c|}{ Profit $^{*}()$} \\
\hline Case & $\begin{array}{c}21-27^{\text {th }} \\
\text { January }^{\text {2use-1 }}\end{array}$ & $\begin{array}{c}20-26^{\text {th }} \\
\text { April }\end{array}$ & $\begin{array}{c}20-26^{\text {th }} \\
\text { July }\end{array}$ & $\begin{array}{c}15-21^{\text {st }} \\
\text { October }\end{array}$ & Total & VSS \\
\hline Case-2 & 946 & 6208.4 & 7121.6 & 1474.9 & 16149.4 & $1663.4(10.3 \%)$ \\
\hline Case-3 & 880.4 & 6009.7 & 6888.4 & 1197.4 & 14975.9 & $1241.5(8.29 \%)$ \\
\hline Case-4 & 420.7 & 5795.9 & 6645.8 & 932.3 & 13794.7 & $1133.9(8.22 \%)$ \\
\hline Case-5 & 422.3 & 5866.4 & 7041.1 & 940.4 & 14270.2 & - \\
\hline
\end{tabular}

discharging of BESS. Moreover, it is shown that the prosumer could gain a profit from the difference between the day-ahead and the regulation market prices. Sensitivity analysis shows that the proposed approach could significantly increase the profitability of the prosumer (i.e. up to $11.6 \%$ with increasing BESS size). The benefit of the two-stage stochastic model over the deterministic counterpart is illustrated by VSS, which is $8.2-10.3 \%$, depending on the cases.

However, it is not clear which capacity of BESS must be utilized, thus a further cost-benefit analysis should be deployed and is left for future research.

\section{REFERENCES}

[1] N. Sommerfeldt, H. Muyingo, T. Klintberg, B. Palm, F. Björk, H. Madani, "Photovoltaic Systems for Swedish Prosumers: A technical and economic analysis focused on cooperative multi-family housing," Available Online: http://kth.diva-

portal.org/smash/record.jsf?pid=diva2\%3A917873\&dswid=4352

[2] J. M. Christine Lins and A. Zervos, "Re-thinking 2050: A 100\% renewable energy vision for the European Union," 2010.

[3] A.Attarha, N. Amjady, S. Dehghan, "Affinely Adjustable Robust Bidding Strategy for a Solar Plant Paired with a Battery Storage," IEEE Trans. Smart Grid, Feb. 2018.

[4] H. Akhavan-Hejazi, B. Asghari, R. K. Sharma, "A joint bidding and operation strategy for battery storage in multi-temporal energy markets," 2015 IEEE PES Innovative Smart Grid Technologies Conference (ISGT), Feb. 2015.

[5] M. Kazemi, H. Zareipour, N. Amjady, W. D. Rosehart, Mehdi Ehsan, "Operation Scheduling of Battery Storage Systems in Joint Energy and Ancillary Services Markets," IEEE Trans. Sustainable Energy, vol. 8, no.4, pp. $1726-1735,2017$

[6] G. He, Q. Chen, C. Kang, P. Pinson, Q. Xia, "Optimal Bidding Strategy of Battery Storage in Power Markets Considering Performance-Based Regulation and Battery Cycle Life," IEEE Trans. Smart Grid, vol. 7, no. 5, pp. $2359-$ 2367, 2015.

[7] H. Akhavan-Hejazi, H. Mohsenian-Rad, "Optimal Operation of Independent Storage Systems in Energy and Reserve Markets with High Wind Penetration," IEEE Trans. Smart Grid, vol. 5, no. 2, pp. 1088-1097, 2014.

[8] G. C. Lazaroiu, V. Dumbrava, G. Balaban, M. Longo, D. Zaninelli, "Stochastic optimization of microgrids with renewable and storage energy systems," 2016 IEEE 16th International Conf. on Environment and Electrical Eng. (EEEIC), June 2016.

[9] Nordpool web page (2018, June 27). Available online: http://www.nordpoolspot.com/

[10] Esset web page (2018, June 27). Available online: https://www.esett.com/handbook/

[11] Private communication with experts from Svenska kraftnät.

[12] Pierre Bonami and Jon Lee, "BONMIN Users' Manual," August 24, 2007.

[13] Z. Norwood, E. Nyholm, T. Otanicar, F. Johnsson, "A Geospatial Comparison of Distributed Solar Heat and Power in Europe and the US," Available online: http://journals.plos.org/plosone/article/authors?id=10.1371/journal.pone.01124 42

[14] A. J. Conejo, M. Carrión, and J. M. Morales, Decision Making under uncertainty in Electricity Markets, vol. 153. Boston MA: Springer US, 2010.

[15] GAMS/SCENRED introduced, May 2002, GAMS Distribution 20.6 [Online]. Available at: https://www.gams.com/latest/docs/T_SCENRED.html

[16] J. Soares, B. Canizes, M. Ali Fotouhi Ghazvini, Z. Vale, G. K. Venayagamoorthy, "Two-Stage Stochastic Model Using Benders' Decomposition for Large-Scale Energy Resource Management in Smart Grids," IEEE Trans. Industry App., vol. 53, no. 6, pp. 5905-5914, 2017. 